\title{
Meta-Analysis of the Association of the C677T Polymorphism of the Methylenetetrahydrofolate Reductase Gene with Hyperuricemia
}

\author{
Wen Wei ${ }^{\mathrm{a}, \mathrm{c}}$ Sheng-yuan Liu ${ }^{\mathrm{a}, \mathrm{d}}$ Fang-fang Zeng ${ }^{\mathrm{a}}$ Ling Ma ${ }^{\mathrm{a}}$ Ke-shen $\mathrm{Li}^{\mathrm{b}}$ \\ Bin-you Wang ${ }^{\text {a }}$ \\ a Department of Epidemiology, School of Public Health, Harbin Medical University, and ${ }^{\mathrm{b}}$ Department of Biomedical \\ Engineering, Harbin Engineering University, Harbin, ' Taizhou Center for Disease Control and Prevention, Taizhou, \\ and ${ }^{\mathrm{d}}$ Department of Chronic Diseases, Shenzhen Nanshan Center for Chronic Disease Control, Shenzhen, China
}

\section{Key Words}

C677T $\cdot$ Hyperuricemia $\cdot$ Meta-analysis $\cdot$ MTHFR $\cdot$

Polymorphisms

\begin{abstract}
Background: The association between the MTHFR C677T

polymorphism and hyperuricemia has been investigated in several studies. Although these epidemiological studies have shown that genetic factors are determinants of serum uric acid levels, the power of the association is weak due to the small sample size. Methods: To study whether the MTHFR C677T polymorphism has an effect on hyperuricemia, we carried out a meta-analysis of case-control studies from PubMed, EMBASE and CNKI (China National Knowledge Infrastructure) databases mainly in English and Chinese. We used the odds ratio (OR) as main effect size; explored potential sources of heterogeneity; performed subgroup analyses by race and performed sensitivity analyses of studies meeting the Hardy-Weinberg equilibrium (HWE). Results: Six studies with 1,470 subjects were included in the meta-analysis. Tests for heterogeneity showed the difference in OR among studies was not statistically significant $(p=0.63$, $I^{2}=0$ ). When excluding the study of Caucasians not in $\mathrm{HWE}$,
\end{abstract}

the association remained robust $(\mathrm{OR}=1.82,95 \% \mathrm{Cl}$ 1.52-2.17) in the East Asian subgroup and sensitivity analyses. Conclusions: Although the mechanism of the relationship between the C677T polymorphism and uric acid still remains unclear, these original articles showed that the MTHFR C677T polymorphism may be an independent risk factor for hyperuricemia.

Copyright $\odot 2012$ S. Karger AG, Basel

\section{Introduction}

MTHFR (methylenetetrahydrofolate reductase) is a main regulatory enzyme in the remethylation phase of homocysteine metabolism. A common polymorphism in the MTHFR gene has been identified. Individuals homozygous (C/C) for the MTHFR normal allele yielded a fragment of $142 \mathrm{bp}$; individuals homozygous for the polymorphism (T/T) yielded 2 fragments of 83 and $59 \mathrm{bp}$, and genotype T/C remained 142 bp [1,2]. Individuals with the variant MTHFR T/T genotype have $30 \%$ of the in vitro enzyme activity seen in those with the $\mathrm{C} / \mathrm{C}$ wild type. Heterozygotes (T/C) show $65 \%$ of normal enzyme activity [3].

\section{KARGER}

Fax +4161306 1234 E-Mail karger@karger.ch www.karger.com
(C) 2012 S. Karger AG, Basel

0250-6807/12/0601-0044\$38.00/0

Accessible online at:

www.karger.com/anm
Bin-you Wang

Department of Epidemiology

School of Public Health, Harbin Medical University

No. 157 Baojian Road, Harbin 150081 (China)

Tel. +86 4518750 2960, E-Mail binyouwang@ hotmail.com 
The C677T polymorphism in the MTHFR polymorphism gene $(\mathrm{T} / \mathrm{T})$ results in decreased enzyme activity, and contributes to increased homocysteine levels and low folate levels [4-10]. Indeed, the polymorphism would not influence the concentrations of folic acid, but increase the nutritional needs of folic acid, since it results in the formation of MTHFR with less catalytic activity. The C677T polymorphism has been suggested to be positively associated with the risk of cardiovascular disease and neural tube defects [11]. Recently, a significant positive correlation between plasma homocysteine and serum uric acid has been reported in patients with atherosclerosis and in controls. As biochemical variables, the effect of uric acid on increasing homocysteine levels was independent of age, sex and creatinine levels. A direct association between serum uric acid and plasma homocysteine levels was first observed in subjects with coronary artery disease and attributed to coexisting renal failure and the use of diuretics [12]. Recently, some studies and epidemiological data have implied that elevated serum uric acid is influenced by genetic factors. Motti et al. [13] found a relationship between the MTHFR C677T polymorphism and serum uric acid. The mechanism of this association is not clear. Hyperuricemia is associated with increased production or decreased renal clearance of uric acid [14]. Zuo et al. [15] demonstrated that the MTHFR gene polymorphism may be a risk factor for hyperuricemia in elderly Japanese men. Hong et al. [16] and Yao et al. [17] confirmed this association in Korean elderly and in the Chinese, respectively. Golbahar et al. [18] found that the 5-MTHFR C677T polymorphism contributes to the higher uric acid levels in both males and females [7] and may be a risk factor for hyperuricemia [19]. Recently, Lwin et al. [20] found that C677T MTHFR is not a confounding factor of the relationship between serum uric acid levels and the prevalence of hypertension in Japanese men.

Hyperuricemia can be acquired, drug induced or genetically determined. It is associated with hypertension and gout [21]. In 2008, Uehara and Rosa [2] illustrated that high concentrations of uric acid are associated with an increased risk of developing hyperhomocysteinemia in subjects with the metabolic syndrome genotyped for the C677T polymorphism. In addition, MTHFR genotype frequencies differed from those found in populations of different ethnic backgrounds [22].

There have been no conclusive opinions about the effects and the pooled odds ratios (ORs) of the MTHFR C677T polymorphism as an independent risk factor for hyperuricemia based on large sample studies, so we con- ducted a meta-analysis of previously published studies on the relationship between the MTHFR C667T polymorphism and hyperuricemia.

\section{Methods}

\section{Literature Search}

Two researchers identified studies testing the association between the C677T polymorphism in the MTHFR gene and hyperuricemia by searching PubMed (January 1966 to December 2008), EMBASE (1980-2007) and CNKI (China National Knowledge Infrastructure) by using the MeSH (medical subject heading) terms hyperuricemia, high uric acid, MTHFR, 5,10-methylenetetrahydrofolate reductase and C677. We complemented the database search by searching for additional publications in personal reference lists from original research articles and review articles. We also hand-searched journals, searched the World Wide Web by means of a search engine (http://scholar.google.com/schhp?hl= zh-CN) and e-mailed the authors to obtain relevant articles which did not have an abstract or the full text in journals and databases. There were language restrictions for the search (mainly in English and Chinese).

\section{Selection of Studies and Inclusion Criteria}

Two interviewers independently screened all articles according to the titles and abstracts. Studies were included when meeting the following criteria: (1) case-control design; (2) the MTHFR C677T polymorphism was assessed both among cases and controls; (3) the definition of high uric acid: males $>7.0 \mathrm{mg} / \mathrm{dl}(420$ $\mu \mathrm{mol} / \mathrm{l})$ or $>5.3 \mathrm{mg} / \mathrm{dl}(315.4 \mu \mathrm{mol} / \mathrm{l})$ and females $>6.0 \mathrm{mg} / \mathrm{dl}(360$ $\mu \mathrm{mol} / \mathrm{l})$ or $>4.8 \mathrm{mg} / \mathrm{dl}(285.6 \mu \mathrm{mol} / \mathrm{l})$, and (4) data can be retrieved from publications or the authors. In addition, strict criteria for meeting the Hardy-Weinberg equilibrium (HWE) were also applied for the studies included.

\section{Data Extraction}

All the relevant data were extracted from individual studies, including first author, country, publication time, racial descent of the study population, and the number of cases and controls for each C677T genotype. Frequencies of T and $\mathrm{C}$ alleles were calculated for the cases and the controls from the corresponding genotype distributions.

\section{Statistical Analysis}

We calculated ORs for studies as the risk estimates for associations of the $\mathrm{T}$ allele with the risk of hyperuricemia relative to the $\mathrm{C}$ allele; we also compared homozygotes $\mathrm{T} / \mathrm{T}$ with $\mathrm{C} / \mathrm{C}, \mathrm{T} / \mathrm{C}$ with $\mathrm{C} / \mathrm{C}, \mathrm{T} / \mathrm{T}$ with $\mathrm{T} / \mathrm{C}+\mathrm{C} / \mathrm{C}$ and $\mathrm{T} / \mathrm{T}+\mathrm{T} / \mathrm{C}$ with $\mathrm{C} / \mathrm{C}$, and $\mathrm{ex}-$ pressed effect measures as ORs presented with associated $95 \%$ CIs, and considered a two-sided $\mathrm{p} \leq 0.05$ to be statistically significant.

We used the Q statistic test and $\mathrm{I}^{2}$ metric to identify the heterogeneity of this meta-analysis. Heterogeneity between studies was tested using the Q statistic that is a weighted sum of squares of the deviations of individual study OR estimates from the overall estimate [23]. Since there was an obvious heterogeneity between studies [24], the random effect model was used, which has the effect of giving more weight to the smaller studies than the 


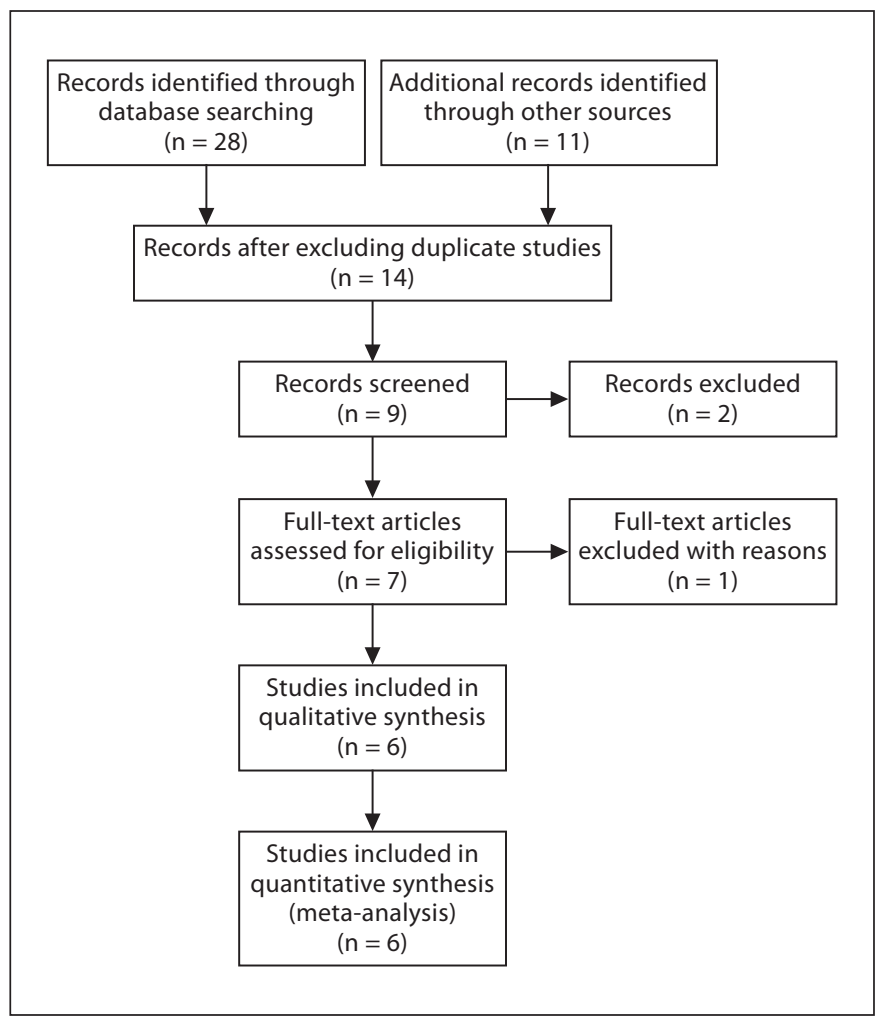

Fig. 1. Flow chart of the study design.

fixed-effect model [25]. When the ORs were homogeneous, Q follows a $\chi^{2}$ distribution with $\mathrm{r}-1$ ( $\mathrm{r}=$ the number of studies) degree of freedom (d.f.). If $\mathrm{p}<0.10$, then the heterogeneity was considered statistically significant. Heterogeneity was quantified with the $\mathrm{I}^{2}$ metric $\left[\mathrm{I}^{2}=(\mathrm{Q}-\mathrm{d}\right.$.f. $\left.) / \mathrm{Q}\right]$, which is independent of the number of studies in the meta-analysis [24]. The $\mathrm{I}^{2}$ takes values between 0 and $100 \%$, with higher values denoting greater degree of heterogeneity $\left(\mathrm{I}^{2}=0-25 \%\right.$, no heterogeneity; $\mathrm{I}^{2}=25-50 \%$, moderate heterogeneity; $\mathrm{I}^{2}=50-75 \%$, large heterogeneity, and $\mathrm{I}^{2}=75-$ $100 \%$, extreme heterogeneity). Other $\mathrm{p}<0.05$ were considered to indicate statistical significance, and all $\mathrm{p}$ values were two sided.

The meta-analysis consisted of the main analysis, which includes all available data, the subgroup analysis of each population and sensitivity analyses, which examine the effect of excluding specific studies. The analyses were performed with Review Manager 4.2, MIX and SAS 9.1 software.

\section{Graphical Evaluation of Publication Bias}

Funnel plots are a visual tool for investigating publication and other bias in meta-analyses [26]. They are simple scatter plots of the effects estimated from individual studies (horizontal axis) against a measure of study size (vertical axis). The name 'funnel plot' is based on the precision in the estimation of the underlying treatment effect, which increases with increasing sample size of component studies. Therefore, in the absence of bias, results from small studies will scatter widely at the bottom of the graph within an inverse funnel shape around the total line (as indicated by the $95 \%$ CIs). Otherwise, it is an indication of publication bias. Mean- while, an asymmetric plot suggested possible publication bias [27]. It is, however, important to realize that publication bias is only one of a number of possible causes of funnel plot asymmetry; funnel plots should be seen as a generic means of examining small study effects (smaller studies in a meta-analysis tend to show larger treatment effects) rather than a tool to diagnose specific types of bias. Furthermore, the possible presence of publication bias was assessed by classic fail-safe N, Begg and Mazumdar's rank correlation test and Egger's test of the intercept [28].

\section{Results}

\section{Selection of Studies and Participant Characteristics}

Nine articles on the association between the C677T polymorphism of the MTHFR gene and hyperuricemia were retrieved after review of titles and abstracts. Two articles with the C677T genotype and uric acid information were excluded, because the detailed information about the association between genotype distribution and hyperuricemia was not available [2,20] (2006/2008). One study [13] from Italy did provide clear information about genotype distributions. In all, 6 citations from 4 countries met the inclusion criteria (fig. 1).

The 6 studies identified in our review varied in characteristics. Two of these were performed in China, 2 in Iran, 1 in Japan and 1 in Korea. All articles included were not only in English, and patients with low uric acid were enrolled as control groups. The mean age of both cases and controls was 50 years (range $40-55$ years). The characteristics of the participants (cases and controls) are shown in table 1 .

In 6 studies, the prevalence of the $\mathrm{T}$ allele was 43 and $30 \%$ for the hyperuricemia and control groups, respectively. The prevalence of T/T homozygotes among patients with hyperuricemia and controls was 16 and $10 \%$, respectively. The prevalence of $\mathrm{C} / \mathrm{C}$ among patients with hyperuricemia and controls was 30 and $49 \%$, respectively. The prevalence of $\mathrm{T} / \mathrm{C}$ heterozygotes among patients with hyperuricemia and controls was 54 and $41 \%$, respectively (table 2). In the study by Golbahar et al. [18], the distribution of genotypes in female cases was not in HWE $\left(\chi^{2}=7.51,0.005<\mathrm{p}<0.010\right)$, indicating genotyping errors and population stratification $[29,30]$. Therefore, a sensitivity analysis should be performed to identify whether it may have exerted a disproportionate influence on the summary effect.

\section{Main Results and Sensitivity Analyses}

Heterogeneity of all 6 studies was assessed using the Q test resulting in a $\mathrm{p}$ value of 0.63 and an $\mathrm{I}^{2}$ value of 0 (CI 
Table 1. Characteristics of the case-control studies included in the meta-analysis

\begin{tabular}{llllllrr}
\hline First author & Year & Country & Racial decent & Mean age, years & Gender & Cases, $\mathrm{n}$ & Controls, $\mathrm{n}$ \\
\hline Golbahar & 2006 & Iran & Caucasian & 50.10 & Male & 115 & 153 \\
Golbahar & 2006 & Iran & Caucasian & 44.50 & Female & 116 & 134 \\
Hong & 2004 & Korea & East Asian & 51.87 & Male & 87 & 240 \\
Shi & 2006 & China & East Asian & 54.50 & Male/Female & 90 & 91 \\
Zuo & 2000 & Japan & East Asian & 52.60 & Male & 58 & 213 \\
Yao & 2007 & China & East Asian & 39.47 & Male & 92 & 81 \\
\hline
\end{tabular}

Table 2. Distribution of MTHFR genotypes and allelic frequencies in patients with and without hyperuricemia (\%)

\begin{tabular}{|c|c|c|c|c|c|c|c|c|c|c|c|c|}
\hline \multirow{3}{*}{$\begin{array}{l}\text { First } \\
\text { author }\end{array}$} & \multirow[t]{3}{*}{ Year } & \multirow{3}{*}{$\begin{array}{l}\text { Racial } \\
\text { decent }\end{array}$} & \multicolumn{5}{|c|}{ Cases $^{\mathrm{a}}, \mathrm{n}$} & \multicolumn{5}{|c|}{ Controls $^{\mathrm{b}}, \mathrm{n}$} \\
\hline & & & \multicolumn{3}{|c|}{ distribution of MTHFR genotypes } & \multicolumn{2}{|c|}{ frequency of MTHFR alleles } & \multicolumn{3}{|c|}{ distribution of MTHFR genotypes } & \multicolumn{2}{|c|}{ frequency of MTHFR alleles } \\
\hline & & & $\mathrm{C} / \mathrm{C}$ & $\mathrm{T} / \mathrm{C}$ & $\mathrm{T} / \mathrm{T}$ & $\mathrm{C}$ & $\mathrm{T}$ & $\mathrm{C} / \mathrm{C}$ & $\mathrm{T} / \mathrm{C}$ & $\mathrm{T} / \mathrm{T}$ & $\mathrm{C}$ & $\mathrm{T}$ \\
\hline Golbahar & 2006 & Caucasian & $48(42)$ & $57(49)$ & $10(9)$ & $153(67)$ & $77(33)$ & $106(69)$ & $41(27)$ & $6(4)$ & $253(83)$ & $53(17)$ \\
\hline Golbahar & 2006 & Caucasian & $39(34)$ & $68(58)$ & $9(8)$ & $146(63)$ & $86(37)$ & $84(63)$ & $44(33)$ & $6(4)$ & $212(79)$ & $56(21)$ \\
\hline Hong & 2004 & East Asian & $20(23)$ & $49(56)$ & $18(21)$ & $89(51)$ & $85(49)$ & $97(40)$ & $113(47)$ & $30(13)$ & 307 (64) & $173(36)$ \\
\hline Shi & 2006 & East Asian & $27(30)$ & $42(47)$ & $21(23)$ & $96(53)$ & $84(47)$ & $40(44)$ & $38(42)$ & $13(14)$ & $118(65)$ & $64(35)$ \\
\hline Zuo & 2000 & East Asian & $15(26)$ & $30(52)$ & $13(22)$ & $60(52)$ & $56(48)$ & $96(45)$ & $92(43)$ & $25(12)$ & $284(67)$ & $142(33)$ \\
\hline Yаo & 2007 & East Asian & $19(20)$ & $53(58)$ & $20(22)$ & $91(49)$ & $93(51)$ & $28(35)$ & $43(53)$ & $10(12)$ & $99(61)$ & $63(39)$ \\
\hline
\end{tabular}

${ }^{a}$ Male $>7.0 \mathrm{mg} / \mathrm{dl}(420 \mu \mathrm{mol} / \mathrm{l})$ or $>5.3 \mathrm{mg} / \mathrm{dl}(315.4 \mu \mathrm{mol} / \mathrm{l})$; female $>6.0 \mathrm{mg} / \mathrm{dl}(360 \mu \mathrm{mol} / \mathrm{l})$ or $>4.8 \mathrm{mg} / \mathrm{dl}(285.6 \mu \mathrm{mol} / \mathrm{l})$.

${ }^{\mathrm{b}}$ Male $\leq 7.0 \mathrm{mg} / \mathrm{dl}(420 \mu \mathrm{mol} / \mathrm{l})$ or $\leq 5.3 \mathrm{mg} / \mathrm{dl}(315.4 \mu \mathrm{mol} / \mathrm{l})$; female $\leq 6.0 \mathrm{mg} / \mathrm{dl}(360 \mu \mathrm{mol} / \mathrm{l})$ or $\leq 4.8 \mathrm{mg} / \mathrm{dl}(285.6 \mu \mathrm{mol} / \mathrm{l})$.

Fig. 2. C677T MTHFR polymorphism and the risk of hyperuricemia: allele $\mathrm{T}$ vs. C. ORs, 95\% CIs and fixed-effect pooled ORs are shown.

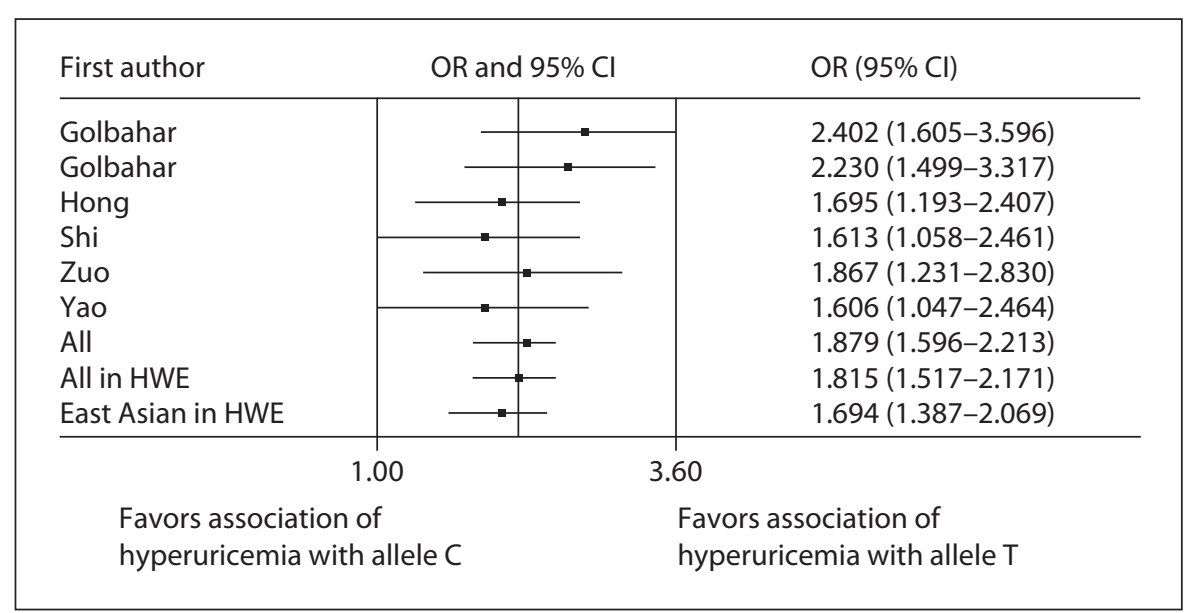

$0-51.49 \%$ ) and data were pooled by the fixed-effect model. Figure 2 and table 3 show the results of individual studies on the association between the $\mathrm{T}$ allele and the risk of hyperuricemia development relative to the $\mathrm{C}$ allele, and corresponding CIs. The combined OR in an overall analysis for study and control groups in the 6 studies was
1.88 (95\% CI 1.60-2.21), indicating an increased risk for the development of hyperuricemia in patients with the C677T polymorphism.

In the sensitivity analysis, when excluding the study of Caucasians not in HWE, the results showed no heterogeneity $\left(p=0.62, I^{2}=0\right)$ and a significant association: fixed- 
Table 3. Distribution of MTHFR genotypes and allelic frequencies in participants with and without hyperuricemia

\begin{tabular}{|c|c|c|c|c|c|c|}
\hline $\begin{array}{l}\text { Genetic } \\
\text { comparisons }\end{array}$ & $\begin{array}{l}\text { Population and } \\
\text { subgroups under analysis }\end{array}$ & Studies & $\begin{array}{l}\text { Alleles/ } \\
\text { genotypes }\end{array}$ & $\begin{array}{l}\text { Fixed-effect } \\
\text { OR }(95 \% \text { CI })\end{array}$ & $\begin{array}{l}\mathrm{I}^{2} \\
\%\end{array}$ & $\begin{array}{l}Q \text { test } \\
\mathrm{p} \text { value }\end{array}$ \\
\hline \multirow[t]{3}{*}{ T vs. C } & all & 6 & 2,940 & $1.88(1.60-2.21)$ & 0 & 0.63 \\
\hline & all in HWE & 5 & 2,440 & $1.82(1.52-2.17)$ & 0 & 0.62 \\
\hline & East Asians in HWE & 4 & 1,904 & $1.69(1.39-2.07)$ & 0 & 0.96 \\
\hline \multirow[t]{3}{*}{ T/T vs. C/C } & all & 6 & 800 & $3.00(2.07-4.34)$ & 0 & 0.99 \\
\hline & all in $\mathrm{HWE}$ & 5 & 662 & $2.97(2.00-4.40)$ & 0 & 0.98 \\
\hline & East Asians in HWE & 4 & 492 & $2.87(1.88-4.38)$ & 0 & 0.96 \\
\hline \multirow[t]{3}{*}{ T/C vs. $\mathrm{C} / \mathrm{C}$} & all & 6 & 1,289 & $2.39(1.86-3.05)$ & 0 & 0.48 \\
\hline & all in HWE & 5 & 1,054 & $2.18(1.65-2.88)$ & 0 & 0.62 \\
\hline & East Asians in HWE & 4 & 802 & $1.91(1.38-2.65)$ & 0 & 0.94 \\
\hline \multirow[t]{3}{*}{$\mathrm{T} / \mathrm{T}$ vs. $\mathrm{T} / \mathrm{C}+\mathrm{C} / \mathrm{C}$} & all & 6 & 1,470 & $1.96(1.41-2.72)$ & 0 & 1.00 \\
\hline & all in HWE & 5 & 1,220 & $1.98(1.40-2.79)$ & 0 & 0.99 \\
\hline & East Asians in HWE & 4 & 952 & $1.93(1.34-2.80)$ & 0 & 0.99 \\
\hline \multirow[t]{3}{*}{$\mathrm{T} / \mathrm{T}+\mathrm{T} / \mathrm{C}$ vs. $\mathrm{C} / \mathrm{C}$} & all & 6 & 1,470 & $2.53(2.00-3.20)$ & 0 & 0.64 \\
\hline & all in HWE & 5 & 1,220 & $2.36(1.81-3.07)$ & 0 & 0.71 \\
\hline & East Asians in HWE & 4 & 952 & $2.12(1.55-2.89)$ & 0 & 0.94 \\
\hline
\end{tabular}

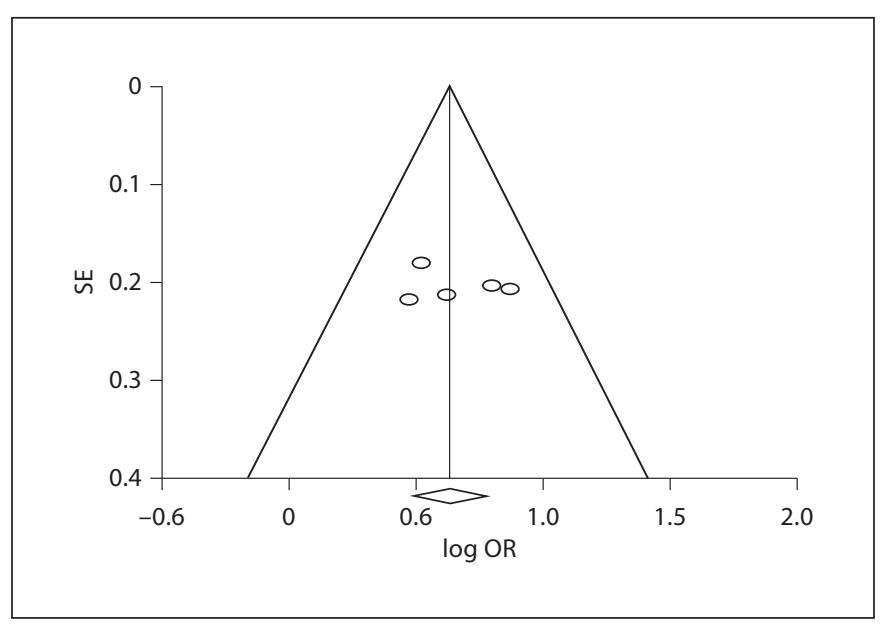

Fig. 3. Funnel plot represents the estimate of summary ORs and $95 \%$ CIs in allele $\mathrm{T}$ vs. C.

effect OR $=1.82$ (95\% CI 1.52-2.17). The subgroup and sensitivity analyses in East Asians without heterogeneity $\left(\mathrm{p}=0.96, \mathrm{I}^{2}=0\right)$ revealed that the association is statistically significant: fixed-effect OR $=1.69$ (95\% CI 1.39-2.07; table 3 , fig. 1). Table 3 presents the results of comparisons among individual genotypes. The genotype contrast of the homozygotes (T/T vs. C/C) produced the same pattern of association with the allele contrast $(\mathrm{OR}=3.00 ; 95 \% \mathrm{CI}$ 2.07-4.34). The $\mathrm{T} / \mathrm{C}$ versus $\mathrm{C} / \mathrm{C}$ contrast also showed that the association between the C677T genotype T/C and the hyperuricemia risk was maintained more than the normal genotype $\mathrm{C} / \mathrm{C}$ in these studies $(\mathrm{OR}=2.39 ; 95 \% \mathrm{CI}$ 1.86-3.05). A comparison of $\mathrm{T} / \mathrm{T}$ versus $\mathrm{T} / \mathrm{C}+\mathrm{C} / \mathrm{C}$ indicated that the association between the C677T mutation $\mathrm{T} / \mathrm{T}$ homozygotes and the hyperuricemia risk $(\mathrm{OR}=1.96$; 95\% CI 1.41-2.72) was stronger than for T/C + C/C genotypes in these studies. It was also stronger for the 677 $\mathrm{C} \rightarrow \mathrm{T}$ mutation and hyperuricemia in genotype $\mathrm{T} / \mathrm{T}+\mathrm{T} / \mathrm{C}$ versus normal $\mathrm{C} / \mathrm{C}(\mathrm{OR}=2.53$; 95\% CI $2.00-3.20)$.

Figure 3 shows the funnel plot of publication bias with OR values (horizontal axis) and SE of OR (vertical axis). Judged by means of eyeballing, the graphical funnel plot of the 6 case-control studies appears asymmetric. We can assume the possibility of publication bias and we applied the Begg and Mazumdar rank correlation test and Egger's test of the intercept to evaluate the publication bias. The latter is more sensitive than the rank correlation approach, but the sensitivity of both methods is generally lower in meta-analyses based on less than 20 studies [28]. Neither Begg's rank correlation ( $\mathrm{p}=0.260$, two tailed) nor Egger's regression test ( $p=0.994$, two tailed) shows any evidence of publication bias in our study. Based on the classic fail-safe $\mathrm{N}$ method, there must be another 84 null studies in our analysis, which can make the summary OR nonsense. This means that we would need to spot and include 84 'null' studies in order for the combined twotailed $\mathrm{p}$ value to exceed 0.050 . In other words, we would need another 14 studies for every study included for the effect to be nullified. 


\section{Discussion}

This meta-analysis examined the association of MTHFR C677T genotype polymorphisms with the susceptibility to hyperuricemia. Results have shown that the MTHFR genotypes and uric acid levels were significantly associated with high uric acid levels in subjects heterozygous for the MTHFR T allele versus the $\mathrm{C}$ allele, the same as in homozygous $\mathrm{T} / \mathrm{T}$ to $\mathrm{C} / \mathrm{C}$ genotype comparison.

Several twin studies as well as epidemiological data about ethnic groups have suggested that genetic factors could modify serum uric acid levels [31-33]. However, only two genetic disorders in which germline polymorphisms cause hyperuricemia have been identified: HPRT (hypoxanthine-guanine phosphoribosytransferase) deficiency [34] and mutant PRPP (phosphoribosylpyrophosphate) synthetase $[35,36]$.

The association of the MTHFR C677T polymorphism with hyperuricemia observed in these studies is in agreement with an Italian study [13]. Hyperuricemia has been associated with conditions of increased production or decreased renal clearance of uric acid. In addition, the C677T MTHFR polymorphism may exert its atherogenic role at least partially through other established risk factors. Regarding hyperuricemia, which has been considered a marker of renal dysfunction and a risk factor for the progression of renal failure, the C677T polymorphism has also been regarded as a risk factor involved in multiple metabolic pathways for ischemic heart disease and stroke [37]. In elderly patients with gout, although uric acid was thought to be an inert end product of purine metabolism without physiological significance, we have also identified one of the genetic factors associated with hyperuricemia: the C677T MTHFR polymorphism. Importantly, the MTHFR C677T genotype had a positive effect on hyperuricemia development by stratifying the genotypes studied (HWE). A significant association between the MTHFR C677T polymorphism and hyperuricemia was found in $\mathrm{T} / \mathrm{T}+\mathrm{T} / \mathrm{C}$ versus $\mathrm{C} / \mathrm{C}$. The MTHFR C677T genotype was also found to be an independent marker of hyperuricemia in elderly men [15].

However, in our analysis of middle-aged and elderly females and males, the relationship between the MTHFR C677T genotype and hyperuricemia was in contrast to preliminary studies. They revealed that this effect is absent in young or elderly women. We suggested that this conflicting view owed to the small sample size of our study, a limitation of our meta-analysis, or it was a new principal finding.

C677T Polymorphisms and

Hyperuricemia
On the other hand, MTHFR genotype frequencies differed from those found in populations of different ethnic backgrounds [22]. In particular, the frequency of subjects with the T/T genotype $(16.13 \%, 95 \%$ CI $12.31-20.81)$ is among the highest ever reported. In European populations (e.g. Finnish or Dutch), the T/T frequency reported is about $5 \%$. For white populations in the US and Australia, the frequency is $11.5 \%$. There seem to be differences in polymorphisms between Caucasian and Asian populations. However, information on Caucasians is scarce. First of all, we only had 2 articles about Caucasians, and 1 did not meet the HWE criteria and was therefore excluded $\left(\chi^{2}=7.51, p<0.05\right)$. Secondly, only 1 article about Caucasians in HWE did not suffice for the meta-analysis to get the three indices [fixed-effect OR with $95 \%$ CI, I ${ }^{2}$ (\%) and $\mathrm{Q}$ test $\mathrm{p}$ value]. Thus, it may explain why we did not do the subgroup analysis on race differences. However, the OR (95\% CI) for East Asians in HWE was 2.87 (95\% CI 1.88-4.38; T/T versus C/C) and the OR for Caucasians in HWE was 3.7 (95\% CI 1.3-10.7). Comparing $\mathrm{T} / \mathrm{C}$ versus $\mathrm{C} / \mathrm{C}$, the $\mathrm{OR}$ in East Asians in HWE was 1.91 (95\% CI 1.38-2.65) compared with 3.1 (95\% CI 1.8-5.2) in Caucasians in HWE. In summary, it was likely that East Asians with T/T and T/C genotype had a lower risk than Caucasians with these genotypes, which has to be confirmed by future research. Further analyses about racial differences are also warranted.

It remains unclear why the MTHFR C677T polymorphism increases the concentration of serum uric acid. Recent research presented two possible mechanisms. First, in subjects with the T/T genotype, renovascular atherosclerosis or the complication of systemic vascular disease may decrease renal clearance of uric acid, resulting in elevated serum uric acid levels [13]. Second, adenosine originating from S-adenosyl-homocysteine, a precursor of homocysteine, could represent a link between the metabolic pathway of homocysteine and serum uric acid. This relationship could be explained by the greater availability of 5,10-methyltetrahydrofolate, a substrate for the MTHFR reaction, for other metabolic pathways such as the de novo synthesis of purines via 10 -formyltetrahyd rofolate with a consequent production of uric acid [15].

\section{Limitations}

Not all studies can be published, thus, any meta-analysis has limitations. If smaller studies without significant results remain unpublished, publication bias may occur in meta-analyses [38]. Although we invested considerable efforts in searching for published studies and 
found as many as we could, our estimates of the effect are still likely to represent overestimation through publication bias and lack of negative articles. Potential sources of asymmetry in funnel plots are: (1) bias in selection, publication, location, language, citation and multiple publication; (2) true heterogeneity: the effect size differs according to the study size, the intensity of the intervention and differences in the underlying risk; (3) data irregularities, poor methodological design of small studies, inadequate analysis and fraud; (4) artifact: heterogeneity due to the poor choice of the effect measure, and (5) chance [28]. These studies were published in English and Chinese. A further limitation of our analysis is that we did not have individual data and were not able to take account of the uncertainty in differences in mean uric acid levels of the groups we retrieved between people with different genotypes in our analysis. In some of these articles, both females and males were studied, and maybe it is better to separate them for gender subgroup analysis.

In conclusion, our meta-analysis provides important evidence for clinical health service. If the association of the MTHFR C677T polymorphism genotype with hyperuricemia is effective, we should pay attention to the possibility of reducing uric acid with the recommendation of folate, vitamin B12 and vitamin B6 intake, which may help to maintain the activity of the enzymes that metabolize homocysteine [3] in individuals with the T/T and $\mathrm{T} / \mathrm{C}$ genotypes, for the polymorphism would increase the nutritional needs of folic acid, since it results in the formation of the thermolabile enzyme MTHFR. Thereby, we could reduce the risk of hyperuricemia in those with MTHFR C677T polymorphism. This strategy requires research in large epidemiological studies in populations with different genetic backgrounds.

\section{Acknowledgments}

We gratefully acknowledge the resource sharing and assistance of Dr. Jamal Golbahar, Faculty of Medicine, Shiraz University of Medical Sciences. We gratefully acknowledge the support of Prof. Edgar J. Love, Department of Community Health Sciences, Faculty of Medicine, University of Calgary, Alta., Canada.

\section{References}

1 Mutchinick OM, López MA, Luna L, Waxman J, Babinsky VE, Ryvemce Collaborative Group: High prevalence of the thermolabile methylenetetrahydrofolate reductase variant in Mexico: a country with a very high prevalence of neural tube defects. Mol Genet Metab 1999;68:461-467.

-2 Uehara SK, Rosa G: Association of homocysteinemia with high concentrations of serum insulin and uric acid in Brazilian subjects with metabolic syndrome genotyped for C677T polymorphism in the methylenetetrahydrofolate reductase gene. Nutr Res 2008; 28:760-766

- 3 Frosst P, Blom HJ, Milos R, Goyette P, Sheppard CA, Matthews RG, Boers GJH, den Heijer M, Kluijtmans LAJ, van den Heuvel LP, Rozen R: A candidate genetic risk factor for vascular disease: a common mutation in methylenetetrahydrofolate reductase. Nat Genet 1995;10:111-113.

-4 Deloughery TG, Evans A, Sadeghi A, McWilliams J, Henner WD, Taylor LM, Press $\mathrm{RD}$ : Common mutation in methylenetetrahydrofolate reductase. Correlation with homocysteine metabolism and late-onset vascular disease. Circulation 1996;94:30743078 .
5 Harmon DL, Woodside JV, Yarnell JW, McMaster D, Young I, McCrum E, Gey K, Whitehead A, Evans AE: The common 'thermolabile' variant of methylenetetrahydrofolate reductase is a major determinant of mild hyperhomocysteinaemia. Q J Med 1996;89: 571-577.

-6 Jacques PF, Bostom AG, Williams RR, Ellison RC, Eckfeldt JH, Rosenberg IH, Selhub J, Rozen R: Relation between folate status, a common mutation in methylenetetrahydrofolate reductase, and plasma homocysteine concentrations. Circulation 1996:93:7-9.

7 Ma J, Stampfer MJ, Hennekens CH, Frosst P, Selhub J, Horsford J, Malinow MR, Willett WC, Rozen R: Methylenetetrahydrofolate reductase polymorphism, plasma folate, homocysteine, and risk of myocardial infarction in US physicians. Circulation 1996;94: 2410-2416.

-8 Malinow MR, Nieto FJ, Kruger WD, Duell PB, Hess DL, Gluckman RA, Block PC, Holzgang CR, Anderson PH, Seltzer D, Upson B, Lin QR: The effects of folic acid supplementation on plasma total homocysteine are modulated by multivitamin use and methylenetetrahydrofolate reductase genotypes. Arterioscler Thromb Vasc Biol 1997; 17:1157-1162.
-9 Schwartz SM, Siscovick DS, Malinow MR, Rosendaal FR, Beverly RK, Hess DL, Psaty BM, longstreth WT Jr, Koepsell TD, Raghunathan TE, Reitsma PH: Myocardial infarction in young women in relation to plasma total homocysteine, folate, and a common variant in the methylenetetrahydrofolate reductase gene. Circulation 1997;96:412-417.

10 Verhoef P, Kok FJ, Kluijtmans LA, Blom HJ, Refsum H, Ueland PM, Kruyssen DACM: The 677CT mutation in the methylenetetrahydrofolate reductase gene: associations with plasma total homocysteine levels and risk of coronary atherosclerotic disease. Atherosclerosis 1997; 132:105-113

11 Wilcken DEL, Wang XL, Wilcken B: Methylenetetrahydrofolate reductase (MTHFR) mutation, homocyst(e)ine, and coronary artery disease. Circulation 1997;96:2738-2740.

12 Kang SS, Wong PWK, Cook HY, Norusis M, Messer JV: Protein-bound homocysteine: a possible risk factor for coronary artery disease. J Clin Invest 1986;77:1482-1486.

13 Motti C, Gnasso A, Bernardini S, Massoud R, Pastore A, Rampa P, Federici G, Cortese C: Common mutation in methylenetetrahydrofolate reductase. Correlation with homocysteine and other risk factors for vascular disease. Atherosclerosis 1998;139:377-383. 
14 Beckler MA, Roessler BJ: Hyperuricemia and gout; in Scriver CR, Beaudet AL, Sly WS, Valle D (eds): The Metabolic Basis of Inherited Disease. New York, McGraw-Hill, 1995, pp 1655-1677.

- 15 Zuo M, Nishio H, Lee MJ, Maejima K, Mimura S, Sumino K: The C677T mutation in the methylene tetrahydrofolate reductase gene increases serum uric acid in elderly men. J Hum Genet 2000;45:257-262.

$\checkmark 16$ Hong YS, Lee MJ, Kim KH, Lee SH, Lee YH, Kim BG, Jeong B, Yoon HR, Nishio H, Kim JY: The C677 mutation in methylene tetrahydrofolate reductase gene: correlation with uric acid and cardiovascular risk factors in elderly Korean men. J Korean Med Sci 2004; 19:209-213.

- 17 Yao H, Ding LL, Wang XM, Xu FL: Polymorphisms of methylenetetrahydrofolate reductase C677T and hyperuricemia in males. Ai Bian Ji Bian Tu Bian 2007; 19:50-52.

-18 Golbahar J, Aminzadeh MA, Al-Shboul QM, Kassab S, Rezaian GR: Association of methylenetetrahydrofolate reductase (C677T) polymorphism with hyperuricemia. Nutr Metab Cardiovasc Dis 2006;17:462-467.

-19 Shi HY, Dong YH, Nan HT, Qian WW, Qian RL: The association of methylenetetrahydrofolate reductase (MTHFR) gene C677T mutation with hyperuricemia. Chin J Diabetes 2006; 14:178-181.

-20 Lwin H, Yokoyama T, Yoshiike N, Saito K, Yamamoto A, Date C, Tanaka H: Polymorphism of methylenetetrahydrofolate reductase gene (C677T MTHFR) is not a confounding factor of the relationship between serum uric acid level and the prevalence of hypertension in Japanese men. Circ J 2006; 70:83-87.
21 Yamamoto T: Definition and classification of hyperuricemia. Nippon Rinsho 2008;66: 636-640.

22 Motulsky AG: Nutritional ecogenetics: homocysteine-related arteriosclerotic vascular disease, neural tube defects, and folic acid. Am J Hum Genet 1996;58:17-20.

23 Cochran WG: The combination of estimates from different experiments. Biometrics 1954 10:101-129.

24 Higgins JP, Thompson SG, Deeks JJ, Altman DG: Measuring inconsistency in meta-analyses. BMJ 2003;327:557-560.

25 Copas J, Shi JQ: Meta-analysis, funnel plots and sensitivity analysis. Biostatistics 2000;1: 247-262.

26 Sterne JA, Egger M, Smith GD: Systematic reviews in health care: investigating and dealing with publication and other biases in meta-analysis. BMJ 2001;323:101-105.

-27 Mao R, Fan Y, Jin Y, Bai J, Fu S: Methylenetetrahydrofolate reductase gene polymorphisms and lung cancer: a meta-analysis. J Hum Genet 2008;53:340-348.

28 Sterne JA, Harbord RM: Funnel plots in meta-analysis. Stata J 2004;2:127-141.

29 Silverman EK, Palmer LJ: Case-control association studies for the genetics of complex respiratory diseases. Am J Respir Cell Mol Biol 2000;22:672-675.

>30 Xu J, Turner A, Little J, Bleecker ER, Meyers DA: Positive results in association studies are associated with departure from HardyWeinberg equilibrium: hint for genotyping error? Hum Genet 2002;111:573-574.
31 Whitfield JB, Martin NG: Plasma lipids in twins. Environmental and genetic influences. Atherosclerosis 1983;48:265-277.

32 Emmerson BT, Nagel SL, Duffy DL, Martin NG: Genetic control of the renal clearance of urate: a study of twins. Ann Rheum Dis 1992; 51:375-377.

33 Tuomilehto J, Zimmet P, Wolf E, Taylor R, Ram P, King H: Plasma uric acid level and its association with diabetes mellitus and some biologic parameters in a biracial population of Fiji. Am J Epidemiol 1988;127:321-336.

$>34$ Seegmiller JE: The clinical significance of hyperuricemia. Med Ann Dist Columbia 1967;36:215-218

>35 Sperling O, Wyngaarden JB, Starmer CF: The kinetics of intramolecular distribution of $15 \mathrm{~N}$ in uric acid after administration of $(15 \mathrm{~N})$ glycine. A reappraisal of the significance of preferential labeling of $\mathrm{N}-(3+9)$ of uric acid in primary gout. J Clin Invest 1973; 52:2468-2485.

36 Akaoka I, Fujimori S, Kamatani N, Takeuchi F, Yano E, Nishida Y, Hashimoto A, Horiuchi Y: A gouty family with increased phosphoribosylpyrophosphate synthetase activity: case reports, familial studies, and kinetic studies of the abnormal enzyme. J Rheumatol 1981;8:563-574

$\$ 37$ Fang J, Alderman MH: Serum uric acid and cardiovascular mortality the NHANES I epidemiologic follow-up study, 1971-1992. National Health and Nutrition Examination Survey. JAMA 2000;283:2404-2410.

38 Schork MA: Publication bias and meta analysis. J Hypertens 2003;21:243-245. 